${ }^{1}$ Dr. Moushumi Afrin Eva Resident Medical Officer (RMO) Dept. of Internal Medicine Holy Family Medical College Dhaka

2

Dr. Nasreen Begum

Assistant Professor

Northern International Medical College, Dhaka

${ }^{3}$ Dr. A S M Anawrul Kabir Registrar, Dept. of Surgery

${ }^{4}$ Dr. Khondoker Wasee Ahmed MO, Dept. of Internal Medicine Square Hospital Limited, Dhaka

Dr. Mahbuba Sharmin

Medical Officer

Bangabandhu Sheikh Mujib

Medical University, Dhaka 5

${ }^{6}$ Dr. Sumanta Kumar Saha Assistant Professor Dept. of Medicine

${ }^{7}$ Dr. Md. Bodroddoza Bayazid HMO, Dept of Medicine Dhaka Medical College, Dhaka

${ }^{8}$ Shahriar Hasan (Physio Therapist) Research Assistant BRAC James P Grant School of Public Health BRAC University, Dhaka

3,6

Holy Family Medical College, Dhaka

Correspondence

Dr. Moushumi Afrin Eva Resident Medical Officer (RMO),

Dept. of Internal Medicine, Holy Family Medical College, Dhaka Email:drmoushumi3@gmail.com

\title{
A study on vitamin D level among the patients attending in a private chamber in Dhaka city
}

\author{
MA Eva ${ }^{1}$, N Begum ${ }^{2}$, A S M A Kabir ${ }^{3}$, K W Ahmed ${ }^{4}$, M Sharmin ${ }^{5}$, S K Saha ${ }^{6}$, \\ M B Bayazid ${ }^{7}$, S Hasan ${ }^{8}$
}

\section{Abstract}

Background : Vitamin D deficiency is one of the most neglected public health issues all over the world. Near about 1 billion people round the world suffer from vitamin D deficiency. Most of the countries in Asia having high prevalence of vitamin $\mathrm{D}$ deficiency.

Objective : To find the vitamin D level among the patients attending in a private chamber in Dhaka city

Methodology : A cross sectional observation study was carried out in a renowned diagnostic center of Dhaka city from July 2017 to June 2018. A sample of 1523 adult patients aged 18 years and above, presented with generalized body aches and pains selected conveniently for the study. Blood samples were taken and serum vitamin $D$ levels were measured. In this study, vitamin $D$ concentration below $10 \mathrm{ng} / \mathrm{ml}$ was considered as vitamin $D$ deficiency, 20-30 $\mathrm{ng} / \mathrm{ml}$ as insufficiency, and $30-100 \mathrm{ng} / \mathrm{ml}$ as vitamin D sufficient. Data were analyzed by using SPSS version 22.

Result : Out of 1523 patients $69.5 \%$ were women and $30.5 \%$ men. Urban and rural distribution was $63.16 \%$ and $36.84 \%$ respectively. Among the participants vitamin $D$ deficiency was $54 \%, 35.8 \%$ vitamin $D$ insufficient, and only $9.8 \%$ had normal level of vitamin $D$, regarding age specific deficiency highest $71.8 \%$ was in 71.80 years age group. Out of 1058 female $39.5 \%$ were vitamin $D$ deficient, $45.6 \%$ had insufficient vitamin $D$ level. Only $14.9 \%$ female were found normal level. Age specific deficiency found highest $63.8 \%$ in 61.70 year age group. On the other hand out of 465 male participants, $24 \%$ were vitamin D deficient, $34 \%$ were insufficient and $42 \%$ had normal level vitamin D. Highest deficiency $42.5 \%$ found in age group $61-70$ years.

Conclusion : Considering the study result deficiency was higher among female than male. In female vitamin D deficiency increased after age of 31 year. Vitamin $\mathrm{D}$ deficiency found highest in old age and middle age group. Over all age specific deficiency found significantly highest in 71 - 80 years. In both male and female Vitamin D deficiency was found highest above 61years of age.

DOI: https://doi.org/10.3329/nimcj.v10i2.45475

Northern International Medical College Journal Vol. 10 No. 2 January 2019, Page 393-396

\section{Introduction}

Vitamin D deficiency is a global public health concern, even in tropical regions where the risk of deficiency was previously assumed to be low due to continuous vitamin $D$ synthesis stimulated by exposure to sun. Vitamin $D$ is essential for growth and development of the body. It has been estimated that almost one billion people in the world suffer from vitamin $D$ deficiency or insufficiency. Poor vitamin D status, as indicated by low serum concentrations of 25- hydroxyvitamin $\mathrm{D}[25(\mathrm{OH}) \mathrm{D}]$, has been observed in South Asian populations.. ${ }^{1}$

It is our general belief that vitamin D deficiency is prevalent only in western countries, but actual condition is reverse. It is surprising that in South Asia, $80 \%$ of the apparently healthy population is deficient in vitamin $D(<20 \mathrm{ng} / \mathrm{ml})$ and up to $40 \%$ of the population is severely deficient $(<9 \mathrm{ng} / \mathrm{ml})$. Sachan et al investigated hypovitaminosis $D$ in Lucknow, India and found that $84 \%$ of pregnant women had $25(\mathrm{OH}) \mathrm{D}$ 
values below $22 \mathrm{ng} / \mathrm{mL}$ (the cut-off point in their research. ${ }^{2}$ Siddiqui and Rai found that in Northern Pakistan where sunlight was available in abundance, rickets was a common problem in infants and children. ${ }^{3}$

In under develop and developing countries, the major source of vitamin D for human is exposure to sunlight. Bangladesh is a tropical country of south Asia where sunlight is abundant almost year round. Therefore it seems that the prevalence of vitamin $D$ deficiency among the Bangladeshi is less. A study in northern rural Bangladesh found about one-third of infants aged 1--6 months were vitamin D-deficient. ${ }^{4} \mathrm{~A}$ study was carried out among 18-33 years old Bangladeshi women reported low vitamin $D$ levels in $81 \%$ women despite being exposed to sun for more than 20 hours per week. ${ }^{5}$

Vitamin D has an important role in calcium homeostasis and bone health since its identification in 1921. Vitamin D deficiency leads to bone diseases like rickets in children and osteomalacia in women. Recently found connections between low vitamin D levels and a wide range of other illnesses such as diabetes, different type of cancers, autoimmune diseases, psychological disorders like depression, cardiovascular diseases, hypertension, lumbago, pre-eclampsia. ${ }^{6}$ Following surgery, injury and infection, inadequate vitamin $\mathrm{D}$ levels may lead to poor wound healing. Muscle weakness and muscle pain has long been associated with vitamin $D$ deficiency. Patient with vitamin $D$ deficiency may be misdiagnosed with fibromyalgia. degenerative joints disease arthritis, chronic fatigue syndrome and others disease. ${ }^{7}$

Vitamin $D$ is a fat soluble steroid prohormone mainly produced photochemically in the skin from 7 dehydrocholesterol. Vitamin D consists of 2 bioequivalent forms. Vitamin D2, also known as ergocalciferol, is obtained from dietary vegetable sources and oral supplements. Vitamin D3 (D3), also known as cholecalciferol, is obtained primarily from skin exposure to ultraviolet B (UVB) radiation in sunlight, ingestion of food sources such as oily fish and fortified foods (milk, juices, margarines, yogurts, cereals, and soy), and oral supplements. ${ }^{8}$ Serum $25(\mathrm{OH}) \mathrm{D}$ is considered the best functional indicator of vitamin $D$ status reflecting the sum of cutaneous synthesis and oral intake. Serum $25(\mathrm{OH}) \mathrm{D}$ level can be determined by direct enzyme-linked immunosorbent assay.

Although it is a research issue all over the world, vitamin D deficiency in Bangladesh yet has not been adequately investigated.

\section{Methodology}

This cross sectional observation study was carried out in a renowned diagnostic center of Dhaka from July 2017 to June 2018. Following non probability convenient sampling technique 1523 patients were selected. Patients were between 11 to 80 years old who attended doctor's chamber with back pain and generalized body ache. Written informed consent was taken during enrollment. This study was approved by the ethical review committee of the concern diagnostic center. Privacy and anonymity of the participants were maintained.

Patients with a major medical illness such as hepatic dysfunction, metabolic disorders such as parathyroid, Diabetes Mellitus, significant thyroid dysfunction, renal diseases, any others metabolic bone disorders, malignancies and patients who were on steroid therapy or any anti-osteoporotic medications like hormone replacement therapy as bisphosphonates were excluded.

\section{Vitamin $\mathrm{D}$ analysis}

The serum $25(\mathrm{OH}) \mathrm{D}$ is the most reliable marker of vitamin $\mathrm{D}$ status. Serum $25(\mathrm{OH}) \mathrm{D}$ levels of all participants was measured and result recorded in data collection sheet. In this study, vitamin $D$ concentration below $10 \mathrm{ng} / \mathrm{ml}$ indicates vitamin $D$ deficiency, whereas a concentration of $20-30 \mathrm{ng} / \mathrm{ml}$ is considered insufficient, and a 25(OH)D level of $30-100 \mathrm{ng} / \mathrm{ml}$ indicate vitamin $D$ sufficient. Data were analyzed by using SPSS version 22.

\section{Result}

A total of 1523 patients were included in the study. The age ranged from $11-80$ years. Out of 1523 patients $69.5 \%(n=1058)$ were women and $30.5 \%(n=465)$ were men. Highest percent of population (19.4\%and $10.2 \%$ ) were belonged to 31 to 40 years and 41 to 50 years age group. $71.5 \%$ of the study population belongs to $21-60$ years of age group. About $(63.16 \%)$ of our study population was living in urban location and (36.84\%) were living in rural area. Table - I

\begin{tabular}{|lcc|}
\hline \multicolumn{2}{|c}{ Table - I : Socio-demographic characters of study population } \\
\hline Age group & Number of Patients & Percentage (\%) \\
\hline $11-20$ & 217 & $14.3 \%$ \\
$21-30$ & 266 & $17.4 \%$ \\
$31-40$ & 296 & $19.4 \%$ \\
$41-50$ & 293 & $19.4 \%$ \\
$51-60$ & 237 & $15.5 \%$ \\
$61-70$ & 118 & $7.7 \%$ \\
$71-80$ & 96 & $6.3 \%$ \\
\hline Sex & & \\
\hline Male & 465 & $30.5 \%$ \\
Female & 1058 & $69.5 \%$ \\
\hline Residence & & \\
\hline Urban & 962 & $63.16 \%$ \\
\hline Rural & 561 & $36.84 \%$ \\
\hline
\end{tabular}


Out of the 1523 study subjects, $827(54 \%)$ were Vitamin D deficient, 546(35.8\%) were vitamin D insufficient, and only 150 (9.8\%) patients had normal level of vitamin D. (Table II)

\begin{tabular}{|c|c|c|c|}
\hline Vitamin D & Vitamin D & Frequency (n) & Percent \\
\hline level (ng/ml) & status & & $(\%)$ \\
\hline$>30$ & Normal & 150 & $9.9 \%$ \\
\hline $20-30$ & Insufficient & 546 & $35.8 \%$ \\
\hline$<10$ & deficient & 827 & $54.3 \%$ \\
\hline
\end{tabular}

Highest percent of participants $(71.9 \%)$ with vitamin D deficiency was in 71-80 years age group. Lowest percent $(33.4 \%)$ of the participants belonged to 21 -30years of age (Table III).

Table - III : Serum vitamin D level in different age groups of study population $(n=1523)$

\begin{tabular}{lcccc} 
& Number of & \multicolumn{3}{c}{ Vitamin D status } \\
Age group & Patients & Deficient n(\%) & Insufficient n(\%) & Sufficient n(\%) \\
$10-20$ & 217 & $81(37.4 \%)$ & $73(33.6 \%)$ & $63(29.0 \%)$ \\
$21-30$ & 266 & $89(33.4 \%)$ & $152(57.3 \%)$ & $25(9.3 \%)$ \\
$31-40$ & 296 & $199(67.3 \%)$ & $87(29.4 \%)$ & $10(3.3 \%)$ \\
$41-50$ & 293 & $166(56.6 \%)$ & $102(34.8 \%)$ & $25(8.6 \%)$ \\
$51-60$ & 237 & $144(60.7 \%)$ & $78(32.9 \%)$ & $15(6.4 \%)$ \\
$61-70$ & 118 & $79(66.9 \%)$ & $34(28.8 \%)$ & $5(4.3 \%)$ \\
$71-80$ & 96 & $69(71.9 \%)$ & $20(20.8 \%)$ & $7(7.3 \%)$
\end{tabular}

Out of 1058 female, 418 (39.5\%) were vitamin D deficient and $482(45.6 \%)$ had insufficient vitamin D level. Only 158 (14.9\%) female were found normal level of vitamin D. Among female participant age 61-70 year had the highest percentage 60(63.8\%) of vitamin D deficiency and 118 (52.4\%) was 31-40 age group (Table IV).

\begin{tabular}{|c|c|c|c|c|}
\hline \multirow[b]{2}{*}{ Age group } & \multirow{2}{*}{$\begin{array}{l}\text { Number of } \\
\text { Patients }\end{array}$} & \multicolumn{3}{|c|}{ Vitamin D status } \\
\hline & & Deficient n(\%) & Insufficient n(\%) & Sufficient $n(\%)$ \\
\hline $10-20$ & $48(4.5 \%)$ & $14(29.2 \%)$ & $15(31.3 \%)$ & $19(39.5 \%)$ \\
\hline $21-30$ & $176(16.6 \%)$ & $42(23.8 \%)$ & $80(45.5 \%)$ & $54(30.7 \%)$ \\
\hline $31-40$ & $225(21.26 \%)$ & $118(52.4 \%)$ & $82(36.4 \%)$ & $25(11.2 \%)$ \\
\hline $41-50$ & $264(24.9 \%)$ & $101(38.3 \%)$ & $141(53.4 \%)$ & $22(8.3 \%)$ \\
\hline $51-60$ & $182(17.2 \%)$ & $64(35.2 \%)$ & $100(54.9 \%)$ & $18(9.9 \%)$ \\
\hline $61-70$ & $94(8.8 \%)$ & $60(63.8 \%)$ & $25(26.6 \%)$ & $9(9.6 \%)$ \\
\hline $71-80$ & $69(6.5 \%)$ & $19(27.5 \%)$ & $39(56.6 \%)$ & $11(15.9 \%)$ \\
\hline Total & $1058(100 \%)$ & $418(39.5 \%)$ & $482(45.6 \%)$ & $158(14.9 \%)$ \\
\hline
\end{tabular}

On the other hand out of 465 male participants, 112 (24\%) were vitamin D deficient, 158(34\%) were insufficient and $195(42 \%)$ had normal level vitamin D. Highest deficiency $48(42.3 \%)$ found in age group $61-70$ years (Table V)
Table -V : Vitamin D status in male study population $(n=465)$

\begin{tabular}{lcccc} 
& Number of & \multicolumn{3}{c}{ Vitamin D status } \\
Age group & Patients & Deficient n(\%) & Insufficient n(\%) & Sufficient n(\%) \\
$10-20$ & $15(3.2 \%)$ & $2(13.3 \%)$ & $5(33.3 \%)$ & $8(53.4 \%)$ \\
$21-30$ & $78(16.17)$ & $16(20.5 \%)$ & $21(26.9 \%)$ & $41(52.6 \%)$ \\
$31-40$ & $49(10.5 \%)$ & $9(18.1 \%)$ & $11(22.7 \%)$ & $29(59.2 \%)$ \\
$41-50$ & $84(18.0 \%)$ & $18(21.4 \%)$ & $39(46.4 \%)$ & $27(32.2 \%)$ \\
$51-60$ & $96(20.6 \%)$ & $14(14.5 \%)$ & $26(27.0 \%)$ & $56(58.5 \%)$ \\
$61-70$ & $112(24.0 \%)$ & $48(42.3 \%)$ & $36(32.7 \%)$ & $28(25.0 \%)$ \\
$71-80$ & $31(6.6 \%)$ & $5(16.1 \%)$ & $20(64.6 \%)$ & $6(19.3 \%)$ \\
Total & $\mathbf{4 6 5 ( 1 0 0 \% )}$ & $\mathbf{1 1 2 ( 2 4 \% )}$ & $\mathbf{1 5 8 ( 3 4 \% )}$ & $\mathbf{1 9 5 ( 4 2 \% )}$
\end{tabular}

\section{Discussion}

This study was conducted to assess Vitamin D level among patients attending doctor's chamber in a private clinic in Dhaka. Among the respondents $54.3 \%$ were found deficient in vitamin $D$ and $35.8 \%$ were insufficient only $9.9 \%$ were with normal levels of vitamin D. This result was nearly similar with a study conducted by Riaz et al on 4830 randomly selected citizens of Pakistan found that $53.5 \%$ Vitamin D had deficient levels, $31.2 \%$ were found with insufficient levels and only $15.3 \%$ showed normal serum level. ${ }^{9}$ In our study deficiency of vitamin D level was found highest $(71.9 \%)$ in age group $71-80$ years and insufficient (57.3\%) was found in 21-30 years age group. Different picture was found in a Bangladeshi study done by Hossain HT et al; Highest percentage $(37.5 \%)$ of severely deficient vitamin $D$ level $(<10 \mathrm{ng} / \mathrm{ml})$ was found in $31-50$ years of age. ${ }^{10}$

In our study among female vitamin $D$ sufficient level was highest $(39.2 \%)$ in younger age group $11-20$ years next sufficient level $(30.8 \%)$ was in $21-30$ years. At these ages persons are active remain outside and exposed to sun more. After 31 years of age vitamin $D$ level decreased and deficiency found highest (63.8\%) in old age group $61-70$ years and (52.4\%) middle age group $31-40$ years. Surekha Bhat $M$ et al in their study found highest deficiency (87.76\%) among age group 20-30 years and (79.84\%) in age group $30-40$ years. ${ }^{11}$ In this study among male respondents highest percentage of deficient vitamin $D$ level (42.3\%) found in $61-70$ years of age and insufficient (64.6\%) in age group $71-80$ years. A study done by Surekha Bhat $M$ et al showed opposite picture deficiency was highest (70.45\%) among 20-30 years and insufficiency (22.22\%) found in age group 50-60 years which was reverse to our study result. ${ }^{12}$ It was also revealed from result that sufficient vitamin $D$ level was found highest $(59.2 \%)$ in $31-40$ years age group next highest $(58.5 \%)$ and $(53.4 \%)$ were found in age groups $51-60$ years and $10-20$ years respectively.

In our country male are more exposed to outdoor sun. The current study revealed vitamin $D$ status of male found as deficient, insufficient and sufficient were (24\%), (34\%) and 
$(42 \%)$ respectively on the other hand female vitamin D status found deficient, insufficient and sufficient were (39.5\%), $(45.6 \%)$ and $(14.9 \%)$ respectively. Therefore in this study among male vitamin D status were better than females. A study in Nepal elucidated females were significantly more deficient of vitamin D as compared to male $(70.08 \%$ vs. $75.37 \%)$ $(p=0.016)$. This was due to socio economic status as most of male were exposed to external environment that is working outside at sun for long time. ${ }^{13}$ Study by Roomi et al. in India also found similar outcome, that was female were significantly more deficient than male. ${ }^{13}$

\section{Conclusion}

In conclusion, the prevalence of vitamin D deficiency as well as insufficiency in the present study was higher among female than male. Over all age specific vitamin $D$ deficiency was significantly highest in 71 - 80 years. The highest deficiency and insufficiency in males in the old aged group $(61-70)$ years and 71-80 years. In female vitamin $D$ deficiency found highest in old age group and middle age group. It was also observed that vitamin $D$ deficiency increased after age of 31 year.

\section{Acknowledgement}

The authors would like to express their sincere gratitude to Dr. Nasreen Begum for her sincere cooperation. Also to all participants and Padma diagnostic center for providing support and also Prof. Dr. Kaniz Moula, Consultant, Department of Internal Medicine, United Hospital and Padma diagnostic center,Dhaka for her valuable contribution.

\section{References}

1. HAM Nazmul Ahasan, Aparna Das. Vitamin D Deficiency in South Asian Populations: A Serious Emerging Problem. Editorial, Journal of Enam Medical College; Vol 3 No 2:July 2013

2. Sachan A, Gupta R, Das V, Agarwal A, Pradeep K, Awasthi PK et al. High prevalence of vitamin $D$ deficiency among pregnant women and their newborns in northern India. Am J Clin Nutr 2005; 81: 1060--1064.
3. Siddiqui TS, Rai MI. Presentation and predisposing factors of nutritional rickets in children of Hazara division. J Ayub Med Coll 2005; 17(3): 29--32.

4. Roth $D E$, Shah $M R$, Black RE, Baqui $A H$. Vitamin $D$ status of infants in northeastern rural Bangladesh: preliminary observations and a review of potential determinants. J Health Popul Nutr. 2010 October; 28(5): 458--469.

5. Islam MZ, shamim AA Kemi, V Navanlinna A. Akhtruzzamen M Lakesrne M, et. al. Vitamin $D$ deficiency and low bone status in adult female garment factory worker in Bangladesh. Brit J natu. 2008:99(6)13322-1329

6. Kuryowicz A, Bednarczuk T, Nauman J. The influence of vitamin Ddeficiency on cancers and autoimmune diseases development. Endokrynol Pol 2007; 58(2):140-523,

7. Plotinikoff GA, Quigley JM prevalence of severe hypovitaminosis $D$ in patients with persistent, nonspecific musculoskeletal pain: Mayo Clin Proc 2006; 78:1463-70.

8. Pliz S, Vitamin D status and arterial hypertension: A systematic review. Nat. Rev. cardiol. 2009;6:621-630

9. Riaz $H$, Finlayson AE, Bashir $S$, Hussain S, Mahmood S, Malik $F$, et al. Prevalence of Vitamin D deficiency in Pakistan; implications for the future. Expert Rev Clin Pharmacol 2016;9(2):329-38.

10. Hossain HT, Islam QT, Khandaker MAK, Ahasan HN Study of Serum Vitamin D Level in Different Socio-Demographic Population- A Pilot Study; J Medicine 2018, Vol. 19, No. $122-29$

11. Surekha Bhat M, Lasrado I, Rajeshwari SG, Gururaja A, Prabhu K, et al. (2017) Prevailing Serum Vitamin D Levels among Individuals in South Karnataka. J Bioanal Biomed 9:184-188. doi: 10.4172/1948-593X.1000178

12. Surekha Bhat M, Lasrado I, Rajeshwari SG, Gururaja A, Prabhu K, et al. (2017) Prevailing Serum Vitamin D Levels among Individuals in South Karnataka. J Bioanal Biomed 9:184-188. doi: 10.4172/1948-593X.1000178.

13. Bhatta MP et al .Prevalence of vitamin D deficiency among adult population of Western Region of Nepal International Journal of Medicine Biomedical Sciences. 2016; 1(2):7-12

14. Roomi MA, Farooq A, Ullah E, Lone KP. Hypovitaminosis $D$ and its association with lifestyle factors. Pakistan journal of medical sciences. 2015;31(5):123640. 